$8-2014$

\title{
Non-surgical and Supportive Periodontal Therapy: Predictors of Compliance
}

Efthimia Effie Ioannidou

University of Connecticut School of Medicine and Dentistry

Follow this and additional works at: https://opencommons.uconn.edu/uchcres_articles Cart of the Dentistry Commons

\section{Recommended Citation}

Ioannidou, Efthimia Effie, "Non-surgical and Supportive Periodontal Therapy: Predictors of Compliance" (2014). UCHC Articles Research. 272.

https://opencommons.uconn.edu/uchcres_articles/272 


\title{
Non-surgical and supportive periodontal therapy: predictors of compliance
}

\author{
Chrysoula Delatola $^{1}$, Evagelia Adonogianaki ${ }^{1}$, and Effie loannidou ${ }^{2}$ \\ ${ }^{1}$ Private Practice, Athens, Greece \\ ${ }^{2}$ Department of Oral Health and Diagnostic Sciences, Division of Periodontology, University of \\ Connecticut Health Center, Farmington, CT, USA
}

\begin{abstract}
Aim-To identify predictors of compliance during non-surgical and supportive periodontal therapy (SPT).
\end{abstract}

Materials and Methods-In this retrospective study, demographic, dental, medical data of 427 new patients in a private practice were collected. Data were analysed in statistical models with non-surgical therapy and SPT compliance used as dependent variables.

Results-Of the 427 patients, $17.3 \%$ never agreed to initial therapy, $10.7 \%$ never completed therapy and $20.8 \%$ completed treatment, but never entered SPT. Of the 218 SPT patients, 56\% became non-attenders after a period of 20 months, $33 \%$ were erratic attenders and $10.5 \%$ were regular attenders until the end of the observation period (5.5-6.5 years). Patients became erratic attenders after a mean period of regular attendance of $18.1 \pm 16.2$ months, whereas $49.6 \%$ of the patients, who abandoned SPT, were regular attenders until the time they stopped. In a univariate correlation model, periodontal disease severity emerged as a significant predictor of the completion of non-surgical periodontal therapy $(p=0.01)$. In a multivariate linear regression model, smoking was negatively associated with SPT compliance $(p=0.047)$.

Conclusions-A low compliance of the population was observed. Smoking and periodontal disease severity represented significant, but modest modifiers of a patient compliance with SPT and initial therapy respectively.

\section{Keywords}

compliance; non-surgical periodontal therapy; periodontitis; predictors; supportive periodontal therapy

Chronic periodontitis is a polymicrobial biofilm infection (Abusleme et al. 2013) resulting in periodontal attachment loss (Armitage 1999). Chronic periodontitis can be effectively treated by means of mechanical non-surgical and surgical therapy (Badersten et al. 1981,

(C) 2014 John Wiley \& Sons A/S. Published by John Wiley \& Sons Ltd

Address: Chrysoula Delatola, 85 Anastaseos str, Cholargos, Athens 15561, Greece, chryssa_del@hotmail.com.

Conflict of interest

The authors declare that there are no conflicts of interest in this study 
Serino et al. 2001). Evidence has shown the importance of SPT in minimizing long-term tooth loss and controlling disease progression and relapse (Renvert \& Persson 2004). It has been strongly suggested that chronic periodontitis progresses in patients, who drop out during non-surgical therapy and in those, who discontinue or not comply with SPT (Kocher et al. 2000, König et al. 2001, 2002, Fardal et al. 2004, Miyamoto et al. 2006, 2010, Fardal \& Linden 2008, Lorentz et al. 2009, Costa et al. 2011b, Ng et al. 2011).

Different social, behavioural, cultural and economic factors as well as personality traits have been identified as determinants of compliance pattern during periodontal maintenance (Mendoza et al. 1991, Demetriou et al. 1995, Ojima et al. 2005, Lorentz et al. 2009, Costa et al. 2011a). Recently, it has been shown that, although an acute chief complaint was a positive prognostic factor for non-surgical periodontal therapy patient acceptance, it was a negative predictor for its completion (Yeh \& Lai 2011). Furthermore, several studies have investigated the role of dental referral in a patient's periodontal compliance (Fardal et al. 2003, Dockter et al. 2006, Fardal 2006). One of the main reasons for quitting maintenance in the periodontal office was the fact that patients tend to return to their own general dentist for supportive therapy (Fardal 2006). Lastly, additional factors such as a patient's age, gender, periodontal condition and treatment undertaken have been also shown to affect compliance (Demirel \& Efeodlu 1995, Anneken et al. 2001, Ojima et al. 2001, Fardal et al. 2003, Soolari \& Rokn 2003, Famili \& Short 2010).

On the basis of the above, we hypothesized that patient demographic, medical and dental characteristics (age, gender, smoking habits, systemic health condition, severity of periodontal disease, chief complaint and type of referral) may affect the compliance with non-surgical and supportive periodontal therapy. Thus, the aim of this study was to identify predictors of non-surgical periodontal therapy (initiation or completion) as well as supportive periodontal therapy (SPT) compliance.

\section{Materials and Methods}

\section{Study population}

This study was conducted in a private periodontal practice in accordance with the principles outlined in the Declaration of Helsinki. Due to the retrospective nature and the minimal risk for human subjects ethical approval from the Hellenic National Bioethics Commission was not necessary. All electronic dental records from consecutive patients, who visited the periodontal practice in 2005 and 2006, were extracted, de-identified and analysed for an observation period, which ended in July 2011 (5.5-6.5 years). Patients, whose records were included in the study, were either self-referred or referred by other specialists or by general dentists. Diagnosis was made after consideration of the clinical periodontal examination in combination with radiographic examination (full-mouth periapical radiographs or panoramic radiograph). Included were thus new adult patients (>18 years old), who (1) visited the practice for the first time within this period, (2) were diagnosed with periodontitis or gingivitis and (3) were resuming periodontal treatment, whereas past treatment was performed by another periodontist. Excluded were patients, who (1) had incomplete records, (2) were resuming periodontal treatment and past treatment was performed in the same practice, (3) were referred for a "prescription" periodontal surgery such as crown 
lengthening, implant surgery or tooth extractions, (4) had developmental or acquired deformities and conditions and (5) were referred for full-mouth tooth extractions. Emergency treatment was provided as needed. Referral to other specialists was arranged when inter-disciplinary treatment was required.

\section{Demographic, dental and medical survey}

All patients had undergone a standardized procedure that included questionnaire survey on medical, dental history and chief complaint. Patient's age and gender were recorded.

Systemic health condition was classified according to the American Society of Anesthesiologists Physical Status (ASA-PS) classification system and modified by dental considerations (Maloney \& Weinberg 2008). In brief, a systemically healthy patient was defined as P1, a patient with mild systemic disease as P2, one with moderate systemic disease as $\mathrm{P} 3$ and one with severe systemic disease that is constant threat to life as P4. Smoking habit was sufficient to classify a patient in P2 category. Both P2 and P3 categories include patients with diseases under medical control, in contrast with the P4 category. P3 category represents severe diseases and requires medical consultation.

On the basis of smoking, patients who smoked from one to 10 cigarettes daily were classified as light smokers, whereas those, who smoked over 10 cigarettes per day were classified as heavy smokers. Periodontal referral was defined as a patient who was referred by other dentist.

Symptoms (such as bleeding when brushing) causing discomfort for a prolonged period were classified as chronic symptomatic chief complaints (CCs). Symptoms occurring within a few days and constantly interfering with daily functions (i.e. toothache, abscess), were classified as acute CCs. Another reason for the periodontal visit was classified as asymptomatic CC.

\section{Diagnosis of periodontal disease}

Periodontal diagnosis was based on probing depths of six sites per tooth in a full-mouth examination. Periodontitis was classified as severe periodontitis, when there were at least two pockets of $6 \mathrm{~mm}$ or more in inter-proximal areas (not on the same tooth) and moderate periodontitis when there were at least two pockets of $5 \mathrm{~mm}$ in inter-proximal areas (not on the same tooth) (modified from Page \& Eke 2007). Lastly, the cases of neither "moderate" nor "severe" periodontitis, were classified as gingivitis or mild periodontitis.

\section{Periodontal treatment compliance definition}

All patients were treated by the same periodontist (E.A.) and they were mostly self-funded. Patients, who did not consent to periodontal treatment were considered untreated. Patients complying with at least one appointment of periodontal therapy were considered treated. These patients were further divided into two subcategories: (a) patients, who completed treatment if they complied with all appointments of phase I periodontal therapy, including oral hygiene instructions, scaling and root planing and periodontal re-evaluation in 6 weeks post-active treatment and b) patients, who did not complete treatment if they missed any of the above appointments. 


\section{Supportive periodontal treatment compliance}

In terms of supportive periodontal treatment compliance, patients were defined as compliers when their SPT appointments were repeated within 6 month intervals, whereas in any case that the inter-appointment interval was greater than 6 months, they were classified as erratics or non-compliers. Patients, who followed maintenance for a limited period of time, were classified as "patients who abandoned maintenance". Finally, the total period of a patient's regular attendance as well as the overall follow-up was recorded. More specifically, we defined the following compliance categories: (1) No Tx = Phase I therapy was never initiated, (2) Initiated Tx = Phase I therapy was initiated but never completed, (3) Completed $\mathrm{Tx}=$ Phase I therapy was completed, (4) Initiated SPT $=$ SPT was entered but abandoned, (5) Erratic SPT = SPT with erratic attendance and (6) Regular SPT = SPT regular attendance until the end of the observation period.

\section{Statistical analyses}

Prior to all analyses, normal distribution was tested for all variables. Variables that were not normally distributed were logarithmically transformed. All parametric data were compared with one-way anova with post hoc Bonferroni analysis for paired group multiple comparisons. Similarly, non-parametric data were compared with Kruskal Wallis test with post hoc tests adjusted for paired group multiple comparisons. Initiation of non-surgical periodontal therapy, completion of non-surgical periodontal therapy and duration of SPT attendance were used as dependent variables in separate univariate models designed to determine crude correlations as well as to facilitate the predictor variables selection for the multivariate analyses. A p-value of 0.2 was used as the cut-off value for a variable to enter the multivariate regression model. Furthermore, a multivariate linear regression model, restricted to patients on SPT $(\mathrm{n}=218)$ was performed using as dependent variable the time patients remained on maintenance. Tests were declared statistically significant at $p<0.05$. All analyses were conducted with a statistical SPSS software package (IBM, v. 19.0, Armonk, NY, USA).

\section{Results}

A sample of 427 patients was included in this study of whom 242 (56.7\%) females. The average age was $48.3 \pm 12.79$ years. One hundred and fifty-two (35.6\%) were self-referred and $275(64.4 \%)$ were referred. The frequency and distribution of CCs were as follows: 152 (35.6\%) subjects having asymptomatic CCs, 208 (48.7\%) having chronic symptomatic and $67(15.7 \%)$ having acute symptomatic CCs. There were 256 (60\%) non-smokers, 56 (13.1\%) light smokers and 115 (26.9\%) heavy smokers. For systemic health conditions, 146 (34.2\%) were P1, 276 (64.6\%) were P2 and 5 (1.2\%) were P3. The descriptive characteristics of the sample are shown in Table 1.

Overall, $352(82.4 \%)$ subjects suffered from severe periodontitis, $35(8.2 \%)$ from moderate periodontitis and $40(9.4 \%)$ from mild periodontitis or gingivitis showing a statically significant difference in a between-group analysis $(p=0.03)$ (Table 1). More specifically, the post hoc analysis revealed that the statistical significance emerged in the comparisons of the groups "Initiated Tx" with "Completed Tx" $(p=0.01)$ and "Erratic SPT" with "Regular 
SPT" $(p=0.04)$. Seventy-four patients $(17.3 \%)$ never initiated phase I therapy, $46(10.7 \%)$ initiated but did not complete phase I therapy, 89 (20.8\%) completed treatment but never entered SPT (Table 1). Of the 218 SPT patients, 123 (56.5\%) stopped maintenance after a mean period of 20 months (data not shown), 72 (33\%) were erratic attenders (with at least one interval between maintenance appointments $>6$ months) and $23(10.5 \%)$ were regular attenders until the end of the observation period (Table 1). Patients became erratic attenders, after a mean period of regular attendance of $18.1 \pm 16.2$ months, whereas $49.6 \%$ of the patients who stopped SPT were regular attenders until the time they stopped (data not shown).

In a univariate correlation model, none of the independent variables emerged as significant predictor of initiation of periodontal treatment (data not shown) $(p>0.05)$. However, when examining therapy completion, periodontal disease severity showed a positive statistically significant association with treatment completion (data not shown) $(p=0.011, \mathrm{r}=0.212)$. The univariate analysis with SPT duration as dependent variable revealed statistically significant negative association with smoking and systemic health condition (Table 2) ( $p=$ 0.008 and $p=0.012$ respectively). Following a multivariate linear regression analysis, smoking emerged as a significant negative predictor for SPT duration (Table 3) $(p=0.047)$.

\section{Discussion}

This retrospective study was designed to evaluate compliance of periodontal patients in a private practice in Athens, Greece and to investigate the "risk profile" of the non-compliant patient. The results indicated a poor compliance of the population with a mean period of SPT attendance of 20 months. Severity of periodontal disease at the time of diagnosis was positively associated with the completion of non-surgical periodontal therapy, whereas smoking was a negative predictor of the time a patient remained in maintenance.

Of the 427 patients only 218 entered SPT, which was approximately half of the sample. Furthermore, $56 \%$ of the 218 patients who entered SPT stopped maintenance and only $10.5 \%$ were regular attenders until the end of the observation period. Thus, in this Greek population, periodontal compliance was found to be low. The importance of this finding was underlined by the relatively short observation period of up to 6.5 years, which was sufficient enough to provide these results. In an earlier Greek study (Demetriou et al. 1995), a higher compliance was observed (27.4\%). However, there are some methodological differences that might explain this discrepancy. First, the criteria of erratic attendance in this study are stricter than those of Demetriou et al. (1995). At least one interval between maintenance appointments $>6$ months is sufficient to characterize a patient as erratic attender, whereas in the study by Demetriou et al. (1995) patients were characterized as regular attenders when they attended for more than $80 \%$ of the recommended appointments. Second, unlike our study, the study by Demetriou et al. (1995) included only patients, who had proven to be compliant by completing phase I therapy. This study included all consecutive periodontal patients regardless of their decision to proceed with periodontal therapy. When our analysis was limited to patients who completed first phase therapy, compliance approached more the previously reported frequencies but still remained in lower levels. In conclusion, both 
studies reveal the need of oral public health education programs in Greece to enhance the compliance of the population with regular dental care.

In our study, patients who stopped maintenance or became erratic attenders did so after a mean period of approximately 18 to 20 months. According to the latter, the early stages of SPT seem to be the most important period for a patient to understand the necessity of maintenance. Similar results were shown in the study of Checchi et al. (1994) indicating that the first year represented the critical period for subjects to decide whether to follow recommended maintenance therapy. Consequently, reinforcement of motivation has been shown necessary not only during initial treatment but especially in the first years of maintenance. Of the patients who stopped SPT, $49.6 \%$ were regular attenders until the time they stopped. This finding indicates clearly that SPT compliance may be difficult to predict and, consequently, emphasizes the fact that every patient should be addressed and motivated as a possible "drop out".

Patients' chief complaints (CCs) at their first periodontal visit in the study of Yeh \& Lai (2011) were associated with their ultimate compliance to basic periodontal therapy overriding other factors. Acute symptomatic $\mathrm{CC}$ could be a positive predictor to initiate periodontal treatment, but a negative predictor to complete treatment. In this study, acute CC was not found to affect neither the initiation nor the completion of treatment.

No significant relationship was observed between compliance and gender, confirming earlier reports by Mendoza et al. (1991), Checchi et al. (1994), Ojima et al. (2001) and Fardal et al. (2003) but contrasting other studies such as Soolari \& Rokn (2003) and Famili \& Short (2010), which indicate that females are better compliers.

Similarly to the observations of Glavind (1986), Mendoza et al. (1991), Fardal et al. (2003) and Ojima et al. (2001) but contrary to Checchi et al. (1994) and Demetriou et al. (1995), age did not significantly influence the pattern of SPT compliance.

Significant relationship was not established between periodontal status and compliance with SPT as previously reported (Checchi et al. 1994, König et al. 2001, Fardal et al. 2003). However, disease severity was positively associated with the completion of non-surgical therapy. It should be underlined, that although the mentioned association was statistically significant the strength of this relationship was modest $(r=0.212)$. Furthermore, in accordance with Mendoza et al. (1991), smoking status was found a borderline statistically significant negative predictor of SPT compliance $(p=0.047)$. The results indicate that smokers might comply less favourably than non-smokers. This observation, in combination with the well-established role of smoking in the periodontal disease progression (Lorentz et al. 2009), underlines the special attention that should be drawn for smokers.

The main strength of this study was the large sample size of a private practice population treated and maintained by one single periodontist (EA). Therefore, any operator bias was eliminated. However, the principal finding of very low compliance to recommended therapy raises the issue to analyse the high dropout rate. Fardal in 2006 by interviews and assessments of returning non-compliant patients revealed that the main reason for noncompliance was the referral system between dentists and specialists. In this study, dental 
referral did not emerge as a significant predictor of compliance. It would be of interest to further survey the reasons of drop out to have a better insight on the risk factors of compliance. However, such information was not available and a different study design would be necessary to accomplish it.

One limitation of this study originates from the lack of socioeconomic data for the patients included which might have biased the results (Oppenheim et al. 1979, Demetriou et al. 1995). However, the majority of the subjects who have visited this specific private practice were residents of the surrounding suburbs representing the Greek middle class.

Another limitation may be deriving from the definition used for periodontal diagnosis. The authors recognize that as stated in the consensus report of the 5th European Workshop in Periodontology (Tonetti \& Claffey 2005): (a) periodontitis cannot be reflected by measurements of a single variable and (b) attachment loss represents the cumulative experience of periodontitis and should be the primary variable used in studies evaluating risk factors. Although more periodontal parameters (attachment level, bleeding on probing, radiographic bone level) should be combined for an accurate diagnosis, unfortunately, additional periodontal variables were not always available for all the individuals. Thus, the present definition of periodontal disease might have led to overestimation of disease severity.

The sample population presented a wide age range and a variety in the periodontal disease diagnosis. Thus, the interval of 6 months in the determination of erratic attendance has been questioned by recent meta-analysis (Riley et al. 2013) and certainly may not be applicable to every individual. As modern dentistry evolves towards personalized approaches, an individual risk assessment based on systemic, environmental, genetic and periodontal parameters should be developed. Obviously, the retrospective nature of this study did not allow for this personalized dimension in individuals diagnosed with periodontal diseases (gingivitis or periodontitis).

Finally, studies evaluating risk factors, progression of disease and tooth loss during supportive periodontal therapy (Axelsson et al. 2004, Matuliene et al. 2008) have traditionally used longer follow-up periods than this study. Thus, it would be of merit to conduct studies on supportive therapy compliance extending in similar observation periods to identify different patterns of compliance longitudinally. Despite the limitation of a shorter observation period, in this study poor compliance was a reliable outcome.

\section{Conclusion}

Low compliance with periodontal therapy was observed in a private practice patient sample in Greece. Smoking and periodontal disease severity represented significant modifiers of the compliance with SPT and non-surgical therapy respectively. Identifying groups of patients that need additional motivation is of utmost importance to clinicians. However, further studies are needed to verify whether these results are valid in the Greek population. 


\title{
Acknowledgments
}

\author{
Source of funding statement
}

No external funding, apart from the support of the authors' institution, was available for this study.

\section{References}

Abusleme L, Dupuy AK, Dutzan N, Silva N, Burleson JA, Strausbaugh LD, Gamonal J, Diaz PI. The subgingival microbiome in health and periodontitis and its relationship with community biomass and inflammation. The ISME Journal. 2013; 7:1016-1025. [PubMed: 23303375]

Anneken C, Treinen J, Willershausen B. Patients compliance in periodontal therapy: a retrospective investigation on the basis of a clinical group. European Journal of Medical Research. 2001; 6:7582. [PubMed: 11313194]

Armitage GC. Development of a classification system for periodontal diseases and conditions. Annals of Periodontology. 1999; 4:1-6. [PubMed: 10863370]

Axelsson P, Nyström B, Lindhe J. The long-term effect of a plaque control program on tooth mortality, caries and periodontal disease in adults. Results after 30 years of maintenance. Journal of Clinical Periodontology. 2004; 31:749-757. [PubMed: 15312097]

Badersten A, Nilveus R, Egelberg J. Effect of non surgical periodontal therapy. I. Moderately advanced periodontitis. Journal of Clinical Periodontology. 1981; 8:57-72. [PubMed: 6972954]

Checchi L, Pelliccioni GA, Gatto MR, Kelescian L. Patient compliance with maintenance therapy in an Italian periodontal practice. Journal of Clinical Periodontology. 1994; 21:309-312. [PubMed: 8034774]

Costa FO, Miranda Cota LO, Pereira Lages EJ, Medeiros Lorentz TC, Soares Dutra Oliveira AM, Dutra Oliveira PA, Costa JE. Progression of periodontitis in a sample of regular and irregular compliers under maintenance therapy: a 3-Year follow-up study. Journal of Periodontology. 2011b; 82:1279-1287. [PubMed: 21342000]

Costa FO, Miranda Cota LO, Pereira Lages EJ, Vilela Câmara GC, Cortelli SC, Cortelli JR, Costa JE, Medeiros Lorentz TC. Oral impact on daily performance, personality traits, and compliance in periodontal maintenance therapy. Journal of Periodontology. 2011a; 82:1146-1154. [PubMed: 21284547]

Demetriou N, Tsami-Pandi A, Parashis A. Compliance with supportive periodontal treatment in private periodontal practice. A 14-year retrospective study. Journal of Periodontology. 1995; 66:145-149. [PubMed: 7730966]

Demirel K, Efeodlu A. Retrospective evaluation of patient compliance with supportive periodontal treatment. The Journal of Nihon University School of Dentistry. 1995; 37:131-137. [PubMed: 7490605]

Dockter KM, Williams KB, Bray KS, Cobb CM. Relationship between prereferral periodontal care and periodontal status at time of referral. Journal of Periodontology. 2006; 77:1708-1716. [PubMed: 17032114]

Famili P, Short E. Compliance with periodontal maintenance at the University of Pittsburgh: retrospective analysis of 315 cases. General Dentistry. 2010; 58:42-47.

Fardal $\emptyset$. Interviews and assessments of returning non-compliant periodontal maintenance patients. Journal of Clinical Periodontology. 2006; 33:216-220. [PubMed: 16489948]

Fardal Ø, Johannessen AC, Linden GJ. Compliance in a Norwegian periodontal practice. Oral Health \& Preventive Dentistry. 2003; 1:93-98. [PubMed: 15645930]

Fardal Ø, Johannessen AC, Linden GJ. Tooth loss during maintenance following periodontal treatment in a periodontal practice in Norway. Journal of Clinical Periodontology. 2004; 31:550-555. [PubMed: 15191591]

Fardal Ø, Linden GJ. Tooth loss and implant outcomes in patients refractory to treatment in a periodontal practice. Journal of Clinical Periodontology. 2008; 35:733-738. [PubMed: 18498381]

Glavind L. The result of periodontal treatment in relationship to various background factors. Journal of Clinical Periodontology. 1986; 13:789-794. [PubMed: 3464624] 
Kocher T, König J, Dzierzon U, Sawaf H, Plagmann HC. Disease progression in periodontally treated and untreated patients a retrospective study. Journal of Clinical Periodontology. 2000; 27:866872. [PubMed: 11073331]

König J, Plagmann HC, Langenfeld N, Kocher T. Retrospective comparison of clinical variables between compliant and non-compliant patients. Journal of Clinical Periodontology. 2001; 28:227232. [PubMed: 11284535]

König J, Plagmann HC, Rühling A, Kocher T. Tooth loss and pocket probing depths in compliant periodontally treated patients: a retrospective analysis. Journal of Clinical Periodontology. 2002; 29:1092-1100. [PubMed: 12492910]

Lorentz TC, Cota LO, Cortelli JR, Vargas AM, Costa FO. Prospective study of complier individuals under periodontal maintenance therapy: analysis of clinical periodontal parameters, risk predictors and the progression of periodontitis. Journal of Clinical Periodontology. 2009; 36:58-67. [PubMed: 19017035]

Maloney WJ, Weinberg MA. Implementation of the American Society of Anesthesiologists Physical Status classification system in periodontal practice. Journal of Periodontology. 2008; 79:11241126. [PubMed: 18597592]

Matuliene G, Pjetursson BE, Salvi GE, Schmidlin K, Brägger U, Zwahlen M, Lang NP. Influence of residual pockets on progression of periodontitis and tooth loss: results after 11 years of maintenance. Journal of Periodontology. 2008; 35:685-695.

Mendoza AR, Newcomb GM, Nixon KC. Compliance with supportive periodontal therapy. Journal of Periodontology. 1991; 62:731-736. [PubMed: 1765935]

Miyamoto T, Kumagai T, Jones JA, Van Dyke TE, Nunn ME. Compliance as a prognostic indicator: retrospective study of 505 patients treated and maintained for 15 years. Journal of Periodontology. 2006; 77:223-232. [PubMed: 16460248]

Miyamoto T, Kumagai T, Lang MS, Nunn ME. Compliance as a Prognostic Indicator. II. Impact of patient's compliance to the individual tooth survival. Journal of Periodontology. 2010; 81:1280 1288. [PubMed: 20397906]

Ng MC, Ong MM, Lim LP, Koh CG, Chan YH. Tooth loss in compliant and noncompliant periodontally treated patients: 7 years after active periodontal therapy. Journal of Clinical Periodontology. 2011; 38:499-508. [PubMed: 21342213]

Ojima M, Hanioka T, Shizukuishi S. Survival analysis for degree of compliance with supportive periodontal therapy. Journal of Clinical Periodontology. 2001; 28:1091-1095. [PubMed: 11737505]

Ojima M, Kanagawa H, Nishida N, Nagata H, Hanioka T, Shizukuishi S. Relationship between attitudes toward oral health at initial office visit and compliance with supportive periodontal treatment. Journal of Clinical Periodontology. 2005; 32:364-368. [PubMed: 15811053]

Oppenheim GL, Bergman JJ, English EC. Failed appointments: a review. The Journal of Family Practice. 1979; 8:789-796. [PubMed: 429996]

Page RC, Eke PI. Case definitions for use in population-based surveillance of periodontitis. Journal of Periodontology. 2007; 78:1387-1399. [PubMed: 17608611]

Renvert S, Persson GR. Supportive periodontal therapy. Periodontology 2000. 2004; 36:179-195. [PubMed: 15330949]

Riley P, Worthington HV, Clarkson JE, Beirne PV. Recall intervals for oral health in primary care patients. The Cochrane Database of Systematic Reviews. 2013; 12:1-31.

Serino G, Rosling B, Ramberg P, Socransky SS, Lindhe J. Initial outcome and long-term effect of surgical and non-surgical treatment of advanced periodontal disease. Journal of Clinical Periodontology. 2001; 28:910-916. [PubMed: 11686808]

Soolari A, Rokn AR. Adherence to periodontal maintenance in Tehran, Iran. A 7- year retrospective study. Quintessence International. 2003; 34:215-219. [PubMed: 12731604]

Tonetti MS, Claffey N. Advances in the progression of periodontitis and proposal of definitions of a periodontitis case and disease progression for use in risk factor research. Group $\mathrm{C}$ consensus report of the 5th European Workshop in Periodontology. Journal of Clinical Periodontology. 2005; 32:210-213. [PubMed: 16128839] 
Yeh HC, Lai H. Association between patient's chief complaints and their compliance with periodontal therapy. Journal of Clinical Periodontology. 2011; 38:449-456. [PubMed: 21332766] 


\section{Clinical Relevance}

\section{Scientific rationale for the study}

Determination of predictors of patient compliance with initial and supportive periodontal therapy (SPT) is important for clinicians.

\section{Principal findings}

Only $5 \%$ of the population complied regularly with treatment. Abandonment of SPT was not associated with erratic attendance. Periodontal condition and smoking were significant predictors of the compliance with initial therapy and SPT respectively.

\section{Practical implications}

The low compliance and the unpredictability whether a patient will continue to attend SPT underlines the necessity of constant patient motivation. Smoking and mild/moderate forms of periodontal disease should be considered by the clinicians as risk indicators for low compliance. 
Table 1

Basic characteristics of the 427 patients by compliance categories

\begin{tabular}{|c|c|c|c|c|c|c|c|c|}
\hline & \multicolumn{8}{|c|}{ Compliance Categories } \\
\hline & $\begin{array}{l}\text { No Tx } \\
n=74\end{array}$ & 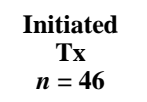 & $\begin{array}{c}\text { Completed } \\
\text { Tx } \\
n=89\end{array}$ & $\begin{array}{c}\text { Initiated } \\
\text { SPT } \\
n=123\end{array}$ & $\begin{array}{c}\text { Erratic } \\
\text { SPT } \\
n=72\end{array}$ & $\begin{array}{c}\text { Regular } \\
\text { SPT } \\
n=23\end{array}$ & $\begin{array}{c}\text { Total } \\
n=427\end{array}$ & $p$-values \\
\hline Age, mean $(\mathrm{SD})$ & $49.5(13.9)$ & $47.8(11.8)$ & $48.7(14.2)$ & $48.1(13.5)$ & $46.9(10.7)$ & $50.7(5.4)$ & $48.3(12.79)$ & 0.76 \\
\hline Male, $n(\%)$ & $34(45.9)$ & $20(43.5)$ & $42(47.2)$ & $52(42.3)$ & $29(40.3)$ & $8(34.8)$ & $185(43.3)$ & 0.88 \\
\hline \multicolumn{9}{|c|}{ ASA-PS classification ${ }^{*}, n(\%)$} \\
\hline P1 & $25(33.8)$ & $18(39.1)$ & $31(34.8)$ & $33(26.8)$ & $30(41.7)$ & $9(39.1)$ & $146(34.2)$ & 0.31 \\
\hline $\mathrm{P} 2$ & $49(66.2)$ & $28(60.9)$ & $58(65.2)$ & $87(70.7)$ & $41(56.9)$ & $13(56.5)$ & $276(64.6)$ & \\
\hline P3 & 0 & 0 & 0 & $3(2.5)$ & $1(1.4)$ & $1(4.4)$ & $5(1.2)$ & \\
\hline P4 & 0 & 0 & 0 & 0 & 0 & 0 & 0 & \\
\hline Referred, $n(\%)$ & $44(59.5)$ & $33(71.7)$ & $57(64.0)$ & $82(66.7)$ & $44(61.1)$ & $15(65.2)$ & $275(64.4)$ & 0.77 \\
\hline \multicolumn{9}{|l|}{ Chief Complaint, $n(\%)$} \\
\hline Asymptomatic & $30(40.5)$ & 15 (32.6) & $36(40.4)$ & $40(32.5)$ & $25(34.7)$ & $6(26.1)$ & $152(35.6)$ & 0.37 \\
\hline Chronic symptomatic & $33(44.6)$ & $23(50.0)$ & 37 (41.6) & $63(51.2)$ & $36(50.0)$ & $16(69.6)$ & $208(48.7)$ & \\
\hline Acute symptomatic & $11(14.9)$ & $8(17.4)$ & $16(18.0)$ & $20(16.3)$ & $11(15.3)$ & $1(4.3)$ & $67(15.7)$ & \\
\hline \multicolumn{9}{|l|}{ Disease severity, $n(\%)$} \\
\hline Mild/gingivitis & $7(9.5)$ & $4(8.7)$ & $17(19.1)$ & $7(5.7)$ & $5(6.9)$ & 0 & $40(9.4)$ & 0.03 \\
\hline Moderate & $8(10.8)$ & $4(8.7)$ & $8(9.0)$ & $11(8.9)$ & $4(5.6)$ & 0 & $35(8.2)$ & \\
\hline Severe & $59(79.7)$ & $38(82.6)$ & $64(71.9)$ & $105(85.4)$ & $63(87.5)$ & $23(100)$ & $352(82.4)$ & \\
\hline \multicolumn{9}{|l|}{ Smoking status, $n(\%)$} \\
\hline Non smokers & $42(56.8)$ & $25(54.3)$ & $53(59.5)$ & $68(55.3)$ & $52(72.2)$ & $16(69.6)$ & $256(60.0)$ & 0.22 \\
\hline Light smokers & $13(17.5)$ & $9(19.5)$ & $8(9.0)$ & $20(16.3)$ & $5(7.0)$ & $1(4.3)$ & $56(13.1)$ & \\
\hline Heavy smokers & $19(25.7)$ & $12(26.1)$ & $28(31.5)$ & $35(28.4)$ & $15(20.8)$ & $6(26.1)$ & $115(26.9)$ & \\
\hline
\end{tabular}

J Clin Periodontol. Author manuscript; available in PMC 2015 June 17. 
Table 2

Univariate correlation analysis between periodontal status, smoking, medical status, gender, age, referral status, CC variables and SPT duration $(n=218)$

\begin{tabular}{lccccccc}
\hline & $\begin{array}{c}\text { Periodontal } \\
\text { Status }\end{array}$ & Smoking & $\begin{array}{c}\text { Medical } \\
\text { Hx }\end{array}$ & Gender & Age & Referral & CC \\
\hline$R$ & 0.026 & $-0.179^{*}$ & $-0.169^{\dagger}$ & -0.053 & -0.016 & -0.041 & -0.038 \\
$p$-value & 0.700 & 0.008 & 0.012 & 0.439 & 0.811 & 0.543 & 0.579 \\
$(2$-tailed) & & & & & & & \\
\hline * & & & & & \\
Correlation is significant at the 0.01 level (2-tailed). \\
${ }^{\dagger}$ Correlation is significant at the 0.05 level (2-tailed).
\end{tabular}




\section{Table 3}

Multivariate linear regression model with smoking and medical status variables as predictors of SPT duration $(n=218)$

\begin{tabular}{lcc}
\hline Variables & B & Sig. \\
\hline Intercept & 1.554 & 0.000 \\
Smoking & -0.075 & $0.047^{*}$ \\
MedHx & -0.074 & 0.242 \\
\hline * Correlation is significant at the 0.05 level.
\end{tabular}

(n)

Conselation is significant at the 0.05 level. 